\title{
CRITERIA FOR BOUNDEDNESS OF FUZZY DIFFERENTIAL EQUATIONS
}

\author{
Y. ZHANG
}

Abstract. The first part of this paper deals with the existence of maximum internal of existence for fuzzy differential equation. Then, using the idea of perturbing Lyapunov functions, is discussed the boundedness of solutions for fuzzy differential equation.

Mathematics subject classification (1991): 34D20, 34A40, 34L99.

Key words and phrases: Fuzzy differential equations, boundedness.

\section{REFERENCES}

[1] D. Dubois And H. Prade, Towards fuzzy differential calculus, Part I, Fuzzy Sets and Systems, 8 (1982), $1-17$.

[2] D. Dubois And H. Prade, Towards fuzzy differential calculus, Part II, Fuzzy Sets and Systems, 8 (1982), 105-116.

[3] D. Dubois And H. Prade, Towards fuzzy differential calculus, Part III, Fuzzy Sets and Systems, 8 (1982), 225-234.

[4] M. Friedman, M. Ming AND A. Kandel, On the validity of the Peano's theorem for fuzzy differential equations, Fuzzy Sets and Systems, 86 (1997), 331-334.

[5] O. KaleVA, Fuzzy differential equations, Fuzzy Sets and Systems, 24 (1987), 301-317.

[6] O. KaLEVA, The Cauchy problem for Fuzzy differential equations, Fuzzy Sets and Systems, 35 (1990), 389-396.

[7] V. LaKShMiKantham and S. G. LeEla, Stability Theory of Fuzzy Differential Equations via Differential Inequalities (to appear).

[8] V. LaKShMiKantham AND R. N. Mohapatra, Basic properties of solutions of fuzzy differential equations (to appear).

[9] V. LaKSHMiKANTHAM AND S. G. LeEla, On perturbing Lyapunov functions, Math. System Theory, 10 (1976), 85-90.

[10] M. L. PuRi AND D. A. RALESCU, Differentials for fuzzy functions, J. Math. Appl., 91 (1983), 552-558. 